\title{
Preparation and Characteristics of Polyaluminium Chloride by Utilizing Fluorine-Containing Waste Acidic Mother Liquid from Clay-Brine Synthetic Cryolite Process
}

\author{
Feng-shan Zhou, ${ }^{1}$ Bo Hu, ${ }^{1,2}$ Bao-lin Cui, ${ }^{1}$ Feng-bao Liu, ${ }^{1,3}$ Fang Liu, ${ }^{1}$ Wei-heng Wang, \\ Yang Liu, ${ }^{1}$ Rong-rong Lu, ${ }^{1}$ Ying-Mo Hu, ${ }^{1}$ Yi-he Zhang, ${ }^{1}$ and Jin-Guang Wu ${ }^{4}$ \\ ${ }^{1}$ School of Materials Science and Technology, China University of Geosciences, Beijing 100083, China \\ ${ }^{2}$ National Library of China, Beijing 100081, China \\ ${ }^{3}$ Tabei Exploratory \& Development Department of PetroChina Tarim Oilfield Company, Korla 841000, China \\ ${ }^{4}$ College of Chemistry and Molecular Engineering, Peking University, Beijing 100871, China
}

Correspondence should be addressed to Feng-shan Zhou; zhoufs@cugb.edu.cn and Yi-he Zhang; zyh@cugb.edu.cn

Received 28 May 2014; Accepted 29 July 2014; Published 17 August 2014

Academic Editor: Chaomeng Dai

Copyright (C) 2014 Feng-shan Zhou et al. This is an open access article distributed under the Creative Commons Attribution License, which permits unrestricted use, distribution, and reproduction in any medium, provided the original work is properly cited.

\begin{abstract}
Clay-brine process employing activated clay, $\mathrm{NaCl}, \mathrm{HCl}$, and $\mathrm{HF}$ as raw materials is the primarily advanced technology to synthesize cryolite in the present industrial grade. However, plenty of byproducts of fluorine-containing waste $\mathrm{HCl}$ at the concentration of about $10 \% \sim 12 \%$ could not be utilized comprehensively and are even hazardous to the environment. This work proposed a new twostep technology to prepare inorganic polymer flocculants polyaluminium chloride (PAC) from synthetic cryolite mother liquor. Many specific factors such as the variety of aluminide source, reaction temperature and time, reagent ratio, and manner of alkaline addition were taken into consideration and their influences on the performances of produced PAC were discussed. It was found that synthetic cryolite mother liquor could react with bauxite and calcium aluminate directly to prepare cheap PAC, with plenty amount of water insoluble $\mathrm{CaF}_{2}$ and $\mathrm{CaSiF}_{6}$ produced as well. However, once $\mathrm{HCl}$ was introduced into synthetic cryolite mother liquor as well as by utilizing bauxite as aluminide source and sodium aluminate as adjusting basicity agent, the resultant PAC would dissolve out higher amount of aluminum while producing little amount of water insoluble materials. The coagulation behavior of the specially produced PAC could even match the industrial grade PAC conforming to national standard.
\end{abstract}

\section{Introduction}

1.1. Cryolite and Clay-Brine Synthetic Process. Cryolite, with professional name sodium aluminum fluoride and molecular formula $\mathrm{Na}_{3} \mathrm{AlF}_{6}$, is a kind of white and small-geometry crystal whose group can be divided into synthetic cryolite and natural cryolite according to the origin of the material itself. It is well recognized that synthetic cryolite possesses much higher solubility than natural cryolite. The other property parameters of synthetic cryolite are as follows: specific gravity 3 , hardness $2 \sim 3$, melting point $1000^{\circ} \mathrm{C}$, and air-slaking after absorption of water. Due to these distinguished properties, cryolite has been applied in diverse fields, among which being utilized as fluxing agent is one of the most common ways. Besides, it is also the significant raw material of aluminium industry. For example, about 100 120 kg cryolite was reported to be consumed to produce $1 \mathrm{t}$ metal-alumina in the present technology [1]. Thus, it is concluded that the large-scale aluminium industry would never exist in this world without cryolite.

There are various kinds of process routes to fabricate cryolite in industry and the raw materials differ greatly from each other accordingly. Among all the technology routes, the most industrial competitive and representative one is the well-known clay-brine process (CBP) employing activated clay, $\mathrm{NaCl}, \mathrm{HCl}$, and $\mathrm{HF}$ as raw materials [2]. The famous Dofluoride Chemicals Co. Ltd. located in Jiaozuo of China is the biggest production corporation in the world to produce synthetic cryolite and the process route it adopts is also the $\mathrm{CBP}$ as shown in Figure 1. 


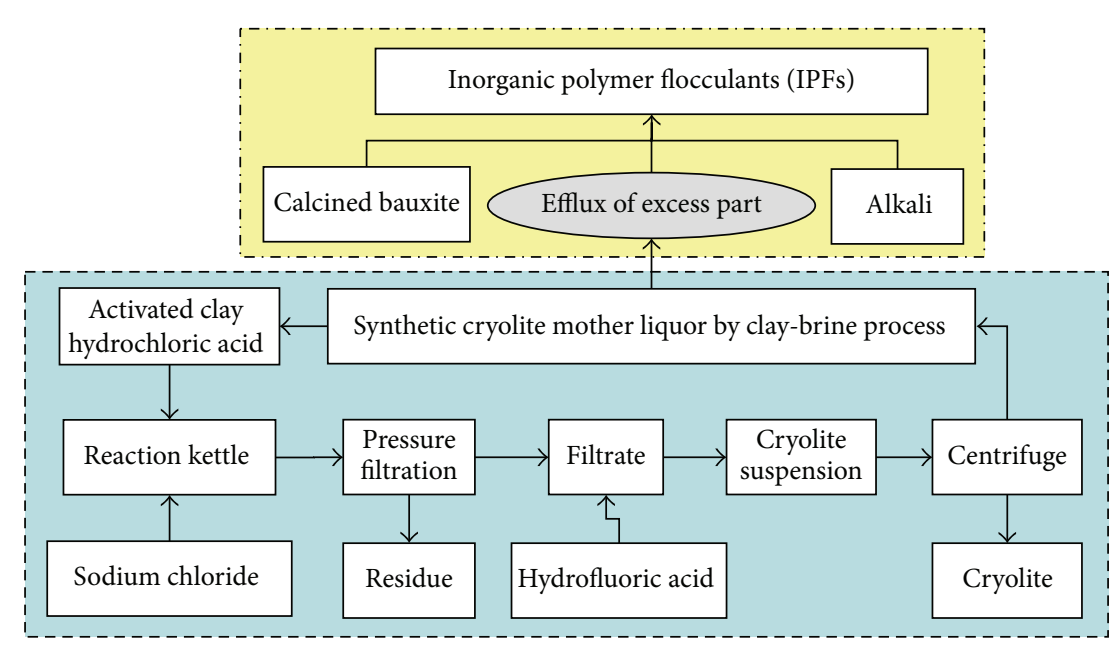

FIGURE 1: Process chart of synthetic cryolite by clay-brine process.

1.2. Features of Cryolite Mother Liquor. Fluorine-containing waste hydrochloric acid from CBP of synthetic cryolite is also commonly known as synthetic cryolite mother liquor (SCML). According to the following CBP reaction principles [2], $6 \mathrm{~mol}$ affiliated $\mathrm{HCl}$ will be produced to fabricate $1 \mathrm{~mol}$ cryolite with $\mathrm{AlCl}_{3}$ as the aluminide source. The amount would even increase to as high as $12 \mathrm{~mol}$ once $\mathrm{AlCl}_{3}$ is replaced by $\mathrm{Al}_{2} \mathrm{O}_{3}$ as the aluminide source. Among the total $12 \mathrm{~mol} \mathrm{HCl}, 6 \mathrm{~mol} \mathrm{HCl}$ would reverse back into the system to leach the clay for cycling utilization. However, the other $6 \mathrm{~mol} \mathrm{HCl}$ would still remain as residue in the system and need to let out for postprocessing, enhancing the complexity as well as the cost of the process route remarkably. It is estimated that $50000 \mathrm{~m}^{3} / \mathrm{a}$ extra acidic synthetic cryolite mother liquor would be created if Do-fluoride Chemicals Co. fabricates 20000 t/a synthetic cryolite [3-5]. Consider

$$
\begin{gathered}
\mathrm{Al}_{2} \mathrm{O}_{3}+6 \mathrm{HCl} \longrightarrow 2 \mathrm{AlCl}_{3}+3 \mathrm{H}_{2} \mathrm{O} \\
\mathrm{AlCl}_{3}+6 \mathrm{HF}+3 \mathrm{NaCl} \longrightarrow \mathrm{Na}_{3} \mathrm{AlF}_{6}+6 \mathrm{HCl} \\
\left(2 \mathrm{AlCl}_{3}+12 \mathrm{HF}+6 \mathrm{NaCl} \longrightarrow 2 \mathrm{Na}_{3} \mathrm{AlF}_{6}+12 \mathrm{HCl}\right)
\end{gathered}
$$

Though SCML from CBP of synthetic cryolite possesses complicated composition as shown in Table $1, \mathrm{~F}^{-}, \mathrm{Cl}^{-}, \mathrm{H}^{+}$, and $\mathrm{Na}^{+}$are four main kinds of ions in it. Meanwhile, the total acidity ranges from $110 \mathrm{~g} / \mathrm{L}$ to $140 \mathrm{~g} / \mathrm{L}$ (or $3 \sim 4 \mathrm{~mol} / \mathrm{L}$ ) (or $10.4 \% \sim 13.8 \%$ ) and the weight percentage of $\mathrm{NaCl}$ is no more than $40 \mathrm{~g} / \mathrm{L}$. This is because the clay utilized in acid leaching is always made from the low grade calcined bauxite with $w\left(\mathrm{Al}_{2} \mathrm{O}_{3}\right) \geq 25 \%$ and $w\left(\mathrm{Fe}_{2} \mathrm{O}_{3}\right) \geq 2.0 \%$.

According to the standard of public water established by the American Environmental Protection Administration (EPA), drinking water with $0.4 \sim 0.6 \mathrm{mg} / \mathrm{L} \mathrm{F}^{-}$will do benefit to human health. However, the situation is not that optimistic when drinking water with $\mathrm{F}^{-}$concentration higher than $1.0 \mathrm{mg} / \mathrm{L}$ for a long time which may even cause serious diseases such as dental and bone fluorosis [4]. In addition, both the difficult controlling of technology and the expensive cost of waste outlet during the treatment process of SCML as acidic waste make corporations suffer from tremendous
TABLE 1: Chemical composition of synthetic cryolite mother liquor (SCML).

\begin{tabular}{lccc}
\hline Anionic ion & $\begin{array}{c}\text { Concentration } \\
(\mathrm{g} / \mathrm{L})\end{array}$ & Cationic ion & $\begin{array}{c}\text { Concentration } \\
(\mathrm{g} / \mathrm{L})\end{array}$ \\
\hline $\mathrm{F}^{-}$ & 18.10000 & $\mathrm{Na}^{+}$ & 24.28000 \\
$\mathrm{Cl}^{-}$ & 139.71000 & $\mathrm{~K}^{+}$ & 0.28402 \\
$\mathrm{CO}_{3}{ }^{2-}$ & 20.00000 & $\mathrm{Ca}^{2+}$ & 0.07636 \\
$\mathrm{SO}_{4}{ }^{2-}$ & 0.75030 & $\mathrm{Mg}^{2+}$ & 0.09012 \\
$\mathrm{SiO}_{3}{ }^{2-}\left(\mathrm{SiO}_{2}\right)$ & 0.01120 & $\mathrm{Fe}^{3+}$ & 3.08000 \\
& & $\mathrm{Al}^{3+}$ & 0.00000 \\
\hline
\end{tabular}

environmental protection pressure [5]. And the enterprise has a great amount of waste acid liquid containing $\mathrm{F}^{-}$, which is badly in need of finding an environmental economy processing method. Meanwhile, it is difficult to polymerize in the preparation of PAC because of the common ion effect of $\mathrm{F}^{-}$. We need to search for a new preparation method in this paper. Thus, this work optimized the process route using SCML to produce inorganic polymer flocculants (IPFs) polyaluminium chloride (PAC). Moreover, the reason for the generation of highly water insoluble materials was well explained via exploration of the XRD phase of products from the reactions. Besides, the well cost performance product PAC was obtained and the optimized route had also been applied in industry.

\section{Materials and Experimental Methods}

2.1. Materials and Instruments. Sodium aluminate, $\mathrm{HCl}$, $\mathrm{HAc}, \mathrm{NaAc}, \mathrm{Zn}(\mathrm{Ac})_{2}, \mathrm{NH}_{3} \cdot \mathrm{H}_{2} \mathrm{O}, \mathrm{KF}$, and EDTA were used for chemical purity. Other purchased industrial grade raw materials included technical hydrochloric acid diluted to $18 \mathrm{wt} \%$; bauxite $\left(\mathrm{Al}_{2} \mathrm{O}_{3} 30 \mathrm{wt} \%\right)$; calcined bauxite $\left(\mathrm{Al}_{2} \mathrm{O}_{3} 40 \mathrm{wt} \%\right)$; calcium aluminate powder $\left(\mathrm{Al}_{2} \mathrm{O}_{3} 53 \mathrm{wt} \%, \mathrm{CaO} 28 \mathrm{wt} \%\right)$; polyaluminium chloride (PAC, $\mathrm{Al}_{2} \mathrm{O}_{3} 29 \mathrm{wt} \%$ ). SCML was the byproduct acid from Do-fluoride Chemicals Co. and the composition was described in Table 1. 
$\mathrm{pH}$ values were determined by $\mathrm{pH} 500$ meter, CLEAN, USA; SGZ-2 turbidimeter was employed to measure turbidity by Shanghai Yuefeng Instruments \& Meters Co., Ltd; COD (potassium dichromate as oxidant) was measured by $5 \mathrm{~B}-6$ COD reactor, Lian-Hua Tech. Co., China.

\subsection{Experimental Methods and Details}

2.2.1. Preparation of PAC from Synthetic Cryolite Mother Liquor. Certain amount of synthetic cryolite mother liquor was added into a three-neck flask with a condenser firstly. After the temperature of the flask was heated to $70^{\circ} \mathrm{C}$ in oil bath, certain amount of bauxite was added into the system step by step. The reaction should continue for $1 \mathrm{~h}$ after the temperature increases to $100^{\circ} \mathrm{C}$. Then alkaline polymerization adjusting agent (APA, calcium aluminate powder, or sodium aluminate powder) was added into the above reaction system gradually to adjust $\mathrm{pH}$ value. The addition speed of APA depended on $\mathrm{pH}$ value of the system: when $\mathrm{pH}$ value was lower than 2.7, the speed can be fast, but when it was over 2.7, the speed should be slow until it increased to 3.5 3.8 further. At this point, APA should not be added into the system any more. After all these operations, the reaction is kept for another $1.5 \mathrm{~h}$ at $100^{\circ} \mathrm{C}$. Then the reaction should be suspended immediately via halting both the vigorous stirring and oil bath heating followed by coagulating the system for $12 \mathrm{~h}$ using the residual heat of oil bath. Liquid PAC was obtained after the filtering of the upper clear liquid of the already stewed reaction suspension. And solid PAC was finally obtained after the initial liquid PAC was dried at $105^{\circ} \mathrm{C}$.

2.2.2. Basicity of the Produced PAC. $\mathrm{OH}^{-}$is the basic component influencing the morphology of polyaluminium chloride [6-9] whose index in PAC is measured by basicity (B). According to GB 15892-2003 (water treatment chemicalpolyaluminium chloride) [10], basicity can be measured. The mol percentage of $\mathrm{OH}$ and $\mathrm{Al}$ in $\mathrm{PAC}$ is defined as basicity and this parameter can reflect the degree of polymerization of PAC to some extent, which affects the coagulation performances of PAC. Basicity can be calculated according to the following during the fabrication process of PAC:

$$
\text { Basicity }=\frac{(\mathrm{OH})}{(\mathrm{Al})} \times 100 \% \text {. }
$$

2.2.3. Coagulation Performance of the Produced PAC. Coagulation tests were performed by using simulated diatomite water and real oily wastewater samples. All coagulation tests were conducted in $100 \mathrm{~mL}$ beakers using a magnetic stirring apparatus. $100 \mathrm{~mL}$ of the test water was placed in a beaker and stirred rapidly at $200 \mathrm{rpm}$ for $2 \mathrm{~min}$ after adding the coagulant at room temperature, followed by slow stirring at $40 \mathrm{rpm}$ for $2 \mathrm{~min}$ and sedimentation for $10 \mathrm{~min}$. Then a supernatant sample was taken at $1.0 \mathrm{~cm}$ below the surface of the test water for turbidity and $\mathrm{COD}_{\mathrm{Cr}}$ measurement.

2.2.4. Characterization of the Produced PAC. The produced PAC solution was dehydrated at $105^{\circ} \mathrm{C}$ and made powder sample for structure analysis. X-ray diffraction (XRD) was measured for the determination of crystalline phases in solid coagulants using D/max-rA X-ray diffractometer with $\mathrm{Cu} \mathrm{K}$ radiation in the $2 \theta$ range of $3^{\circ}$ to $80^{\circ}$ at a scan rate of $8^{\circ} / \mathrm{min}$. The solid produced PAC was analyzed by FT-IR with the Perkin Elmer spectrum 100 FT-IR spectrophotometer and potassium bromide pellet method. The spectra were scanned in the range of 4000 to $500 \mathrm{~cm}^{-1}$.

\section{Results and Discussion}

3.1. Synthesis Optimization. The $\mathrm{pH}$ value of the leaching reaction system was the most critical technological parameter during the fabrication process of PAC [11-13]. Due to the amphoteric compound property of aluminum, the state of aluminum salt solution showed certain transformation law along with $\mathrm{pH}$ value alteration. When the $\mathrm{pH}$ value of the leaching agent was less than 4, aluminum mostly existed as hydrated ions. These hydrated ions would get hydrolysed as $\mathrm{pH}$ value increased, and the mononuclear or monohydroxy compounds would first generate, and then the new produced compounds evolve into three-nuclear or multihydroxy compounds along with further increase of $\mathrm{pH}$ value. In this compound, bridging effect took place between ions and hydroxyl, creating multiple nuclear hydroxyl complexes known as inorganic polymer. The specific states of aluminum salt solution along with $\mathrm{pH}$ value alteration were as follows [13-15]:

$$
\begin{aligned}
& \mathrm{pH}<4,\left[\mathrm{Al}\left(\mathrm{H}_{2} \mathrm{O}\right) n\right]^{3+}, n=6 \sim 10 \\
& 4<\mathrm{pH}<6,\left[\mathrm{Al}_{6}(\mathrm{OH}) 1_{5}\right]^{3+},\left[\mathrm{Al}_{7}(\mathrm{OH}) 1_{7}\right]^{4+}, \\
& {\left[\mathrm{Al}_{8}(\mathrm{OH})_{20}\right]^{4+},\left[\mathrm{Al}_{13}(\mathrm{OH})_{34}\right]^{5+}} \\
& 6<\mathrm{pH}<8,\left[\mathrm{Al}(\mathrm{OH})_{3}\right] \\
& \mathrm{pH}>8,\left[\mathrm{Al}(\mathrm{OH})_{4}\right]^{-},\left[\mathrm{Al}_{8}(\mathrm{OH})_{26}\right]^{2-} .
\end{aligned}
$$

The chemical equations to prepare PAC were indicated as follows:

$$
\begin{gathered}
\mathrm{Al}_{2} \mathrm{O}_{3}+6 \mathrm{HCl} \longrightarrow 2 \mathrm{AlCl}_{3}+3 \mathrm{H}_{2} \mathrm{O} \\
\mathrm{AlCl}_{3}+\mathrm{NaAl}(\mathrm{OH})_{4} \longrightarrow\left[\mathrm{Al}_{2}(\mathrm{OH})_{n} \mathrm{Cl}_{6-n}\right]_{m}+\mathrm{NaCl}
\end{gathered}
$$

According to the above reaction principles, the influencing factors such as the kind and amount of APA, amount of water insoluble material, and leaching aluminum as well as the degree of polymerization (or basicity) were deeply discussed in this work and results were described in Table 2 from which two laws were concluded.

(1) Once synthetic cryolite mother liquor was the only taken acid leaching agent, the leaching efficiency of aluminum was not that high. Nevertheless, it could be enhanced apparently when appropriate $\mathrm{HCl}$ was added into synthetic cryolite mother liquor.

(2) When calcium aluminate was used as APA, $\mathrm{Ca}^{2+}$ would react with $\mathrm{F}^{-}$and $\mathrm{SiO}_{3}{ }^{2-}$ in synthetic cryolite mother liquor and high amount of water insoluble material was thus produced. However, if calcium aluminate was replaced by sodium aluminate as APA, the 
TABLE 2: Optimization experiment to prepare PAC by SCML leaching bauxite.

\begin{tabular}{lccccc}
\hline Sample & Acid & Alkali & $\mathrm{Al}_{2} \mathrm{O}_{3}(\%)$ & Basicity (\%) & Insoluble solid in water (\%) \\
\hline $\mathrm{A}$ & $\mathrm{SCML}$ & Calcium aluminate & 28.7 & 87 & 11.2 \\
$\mathrm{~B}$ & $\mathrm{SCML}+\mathrm{HCl}$ & Calcium aluminate & 29.1 & 79 & 5.8 \\
$\mathrm{C}$ & $\mathrm{SCML}+\mathrm{HCl}$ & Sodium aluminate & 30.2 & 66 & 1.5 \\
\hline
\end{tabular}

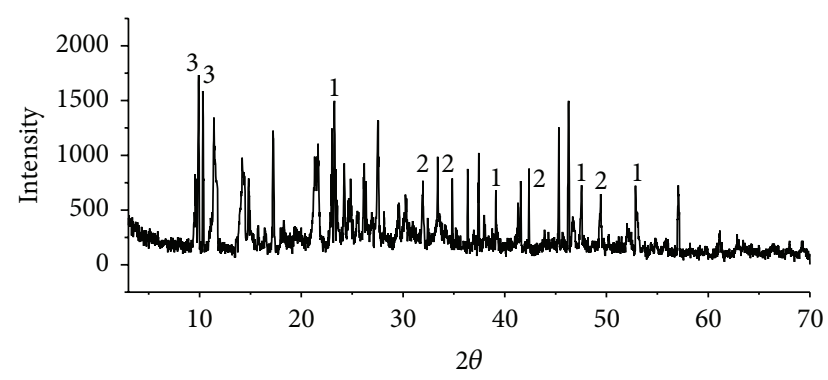

(1) $\mathrm{CaSiF}_{6}$

(2) $\mathrm{CaF}_{2}$

(3) $\mathrm{AlCl}_{3}$

FIGURE 2: XRD spectra of PAC (Sample B) generated from polymerization induced by calcium aluminate as $\mathrm{pH}$ adjusting agent.

amount of water insoluble material would decrease significantly.

Based on the above experimental results, the reaction condition was optimized as follows: $200 \mathrm{~mL}$ mixed acid was obtained first by blending $150 \mathrm{~mL}$ synthetic cryolite mother liquor (containing $\mathrm{HCl} \mathrm{12 \% )} \mathrm{with} 50 \mathrm{~mL}$ industrial $31 \%$ concentrated $\mathrm{HCl} .80 \mathrm{~g}$ bauxite was then added into the mix and the reaction was kept for $1 \sim 2 \mathrm{~h}$ at $80 \sim 100^{\circ} \mathrm{C}$. The polymerization was completed when $23 \mathrm{~g}$ sodium aluminate was added into the system to adjust $\mathrm{pH}$ value followed by coagulation for $12 \mathrm{~h}$ under vigorous stirring. PAC with industrial quality standard could be obtained after the stewing and filtering of the reaction agent.

3.2. Structure of the Produced PAC. The final product following the optimized preparative conditions was analyzed with $\mathrm{XRD}$ and FT-IR to obtain detailed structural information.

XRD spectra of PAC (Sample B) generated from polymerization induced by calcium aluminate as $\mathrm{pH}$ adjusting agent were showed in Figure 2. It was indicated that there appeared characteristic absorption bands assigned to water insoluble $\mathrm{CaF}_{2}$ and $\mathrm{CaSiF}_{6}$ besides the absorption band of $\mathrm{AlCl}_{3}$. This might be because HF in synthetic cryolite mother liquor dissolved $\mathrm{SiO}_{2}$ in calcium aluminate into $\mathrm{SiO}_{3}{ }^{2-}$ and both $\mathrm{SiO}_{3}{ }^{2-}$ and $\mathrm{F}^{-}$encountered $\mathrm{Ca}^{2+}$ leached from calcium aluminate to form water insoluble $\mathrm{CaF}_{2}$ and $\mathrm{CaSiF}_{6}$.

However, in the XRD spectra of PAC (Sample C) generated from polymerization induced by sodium aluminate as $\mathrm{pH}$ adjusting agent (Figure 3), it was not difficult to find that there existed characteristic absorption bands of Fe except for the absorption band of $\mathrm{AlCl}_{3}$. This might be because $\mathrm{HF}$

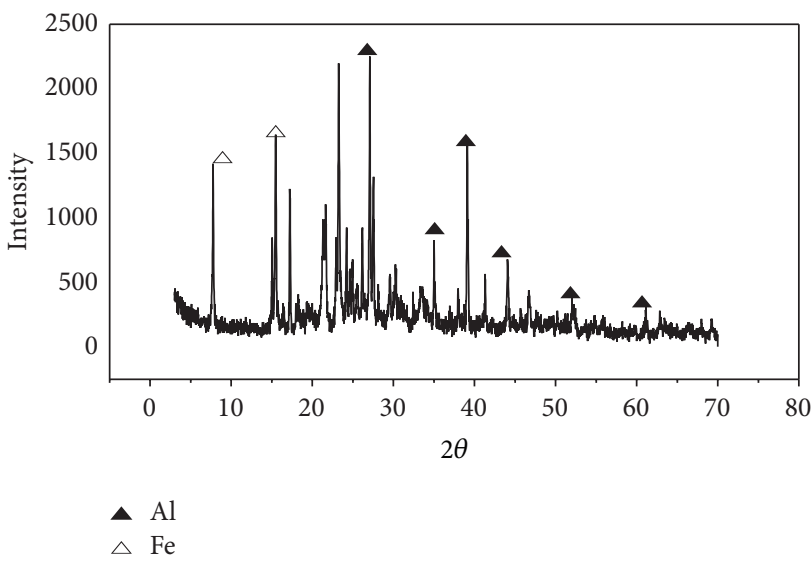

FIGURE 3: XRD spectra of PAC (Sample C) generated from polymerization induced by sodium aluminate as $\mathrm{pH}$ adjusting agent.

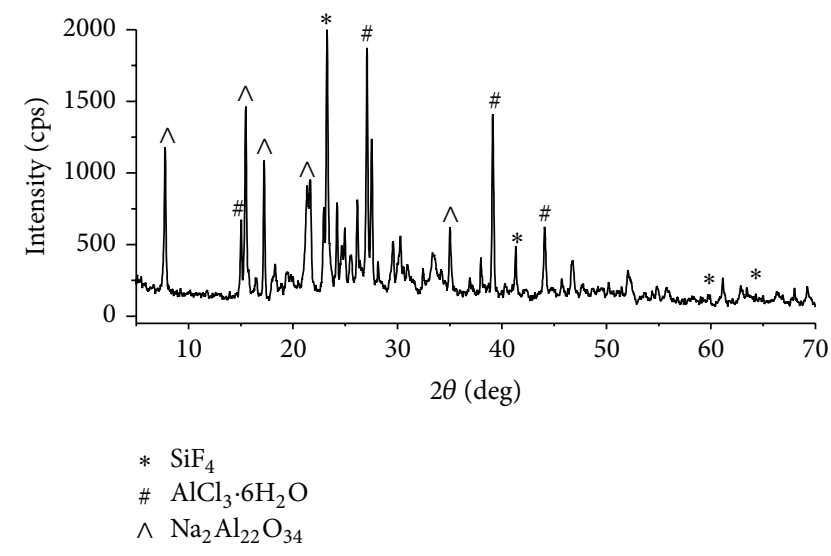

FIGURE 4: XRD spectra of crystal leached from bauxite via SCML and $\mathrm{HCl}$ mixed acid.

and $\mathrm{HCl}$ in synthetic cryolite mother liquor dissolved $\mathrm{Fe}$ in bauxite into $\mathrm{Fe}^{2+}$ and $\mathrm{Fe}^{3+}$, with $\mathrm{Fe}(\mathrm{OH})_{3}$ further produced.

In order to confirm that $\mathrm{Fe}$ in bauxite can be abundantly dissolved out in acid leaching process, SCML and $\mathrm{HCl}$ mixed acid was proposed to leach bauxite. XRD results of the crystal obtained from the dried leaching solution indicated that the main components of this crystal contained $\mathrm{SiF}_{4}$, $\mathrm{AlCl}_{3} \cdot 6 \mathrm{H}_{2} \mathrm{O}$, and $\mathrm{Na}_{2} \mathrm{Al}_{22} \mathrm{O}_{34}$ (Figure 4). Thus, it was clear that PAC prepared from SCML was rather different from industrial grade PAC. Instead, it was made up of multiple crystal phases and components and $\mathrm{AlCl}_{3}, \mathrm{FeCl}_{3}, \mathrm{SiF}_{4}$, and $\mathrm{H}_{2} \mathrm{SiO}_{3}$ were especially typical. The plural gel formed by the polymerization of these components might show synergism effect on the coagulation characteristic of PAC [16-20]. 


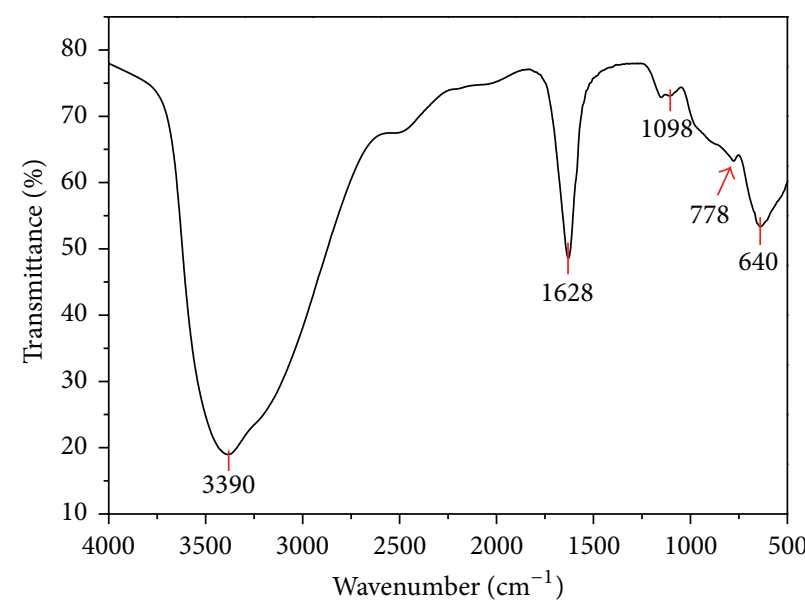

(a)

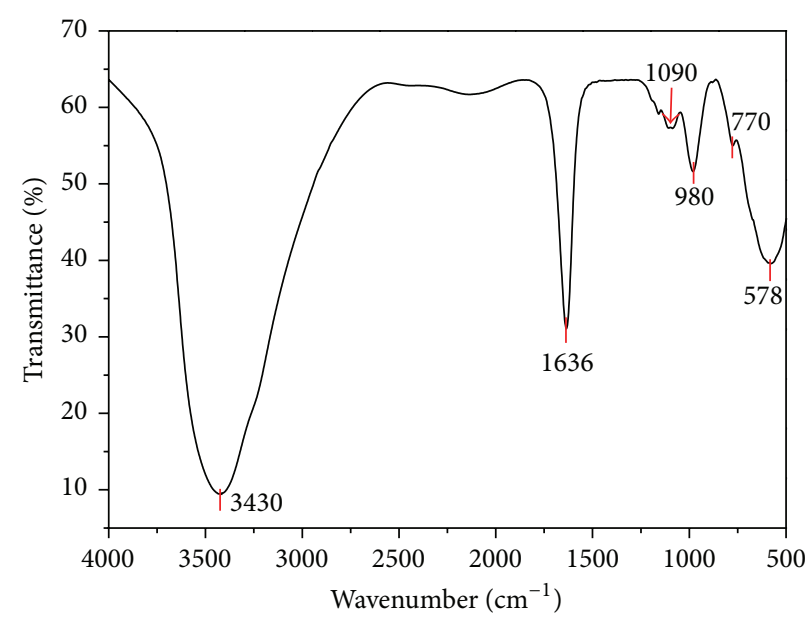

(b)

FIgURE 5: FT-IR spectra for (a) the produced PAC by SCML and (b) industrial grade PAC.

It was well recognized in collochemistry that the positive discharged $\mathrm{Fe}(\mathrm{OH})_{3}$ colloidal particles with small amount in system could create bridged bonds among negative colloidal particles just like coagulating agent, thus getting precipitated via mutual absorption. On this occasion, $\mathrm{Fe}(\mathrm{OH})_{3}$ functioned as coagulant aid $[18,19]$.

The existence of small amount of silica sol (also ludox) not only could promote the coagulating process of water as well as improving the structure of precipitation particles, but also could increase their weight, accelerating the formation and precipitation of precipitation particles. Therefore, silica sol could also function as coagulant aid. Unlike the large amount of positive charge of $\mathrm{Al}_{13}$ as key component of flocculation agent of PAC, the surface of silica gel particles was filled with negative charge instead. Thus, these two kinds of particles with totally opposite charge would allure each other to get absorbed. Meanwhile, silica gel could also absorb other scattered colloidal particles with positive charge, strengthening the coagulating effect accordingly $[15,17,21$, 22].

From the above discussion, it was found that the produced PAC by SCML (PAC-SCML) was rather different from common industrial grade PAC (PAC-IG). Except for the relative strong coagulating character, it was a kind of composite flocculant containing certain amount of $\mathrm{Fe}$ and $\mathrm{Si}$, which could be treated as the compound of PAC, polyaluminum ferric chloride (PAFC), and polysilicate (PSi) [18-20, 23]. Besides, FT-IR spectra of this special PAC showed much difference from that of common PAC as indicated in Figure 5.

The possible chemical bonds in PAC-SCML (Sample C) were investigated by the FT-IR spectra and were compared with PAC-IG (Figure 5). The two samples showed similar FTIR spectra. Both spectra exhibited a broad absorption peak in the range of $3200-3650 \mathrm{~cm}^{-1}\left(3390 \mathrm{~cm}^{-1}\right.$ for PAC-SCML and $3430 \mathrm{~cm}^{-1}$ for PAC-IG), which could be assigned to the stretching vibrations of $-\mathrm{OH}$ groups. The peaks in the range of $1600-1700 \mathrm{~cm}^{-1}\left(1628 \mathrm{~cm}^{-1}\right.$ for PAC-SCML and $1636 \mathrm{~cm}^{-1}$ PAC-IG) were attributed to the bending vibrations of water absorbed, polymerized, and crystallized in the coagulant. The PAC-IG was not a pure substance, which also contains some iron ions. The peak at $1098 \mathrm{~cm}^{-1}$ for PAC-SCML and the peak at $1090 \mathrm{~cm}^{-1}$ for PAC-IG were attributed to the asymmetric stretching vibration of $\mathrm{Fe}-\mathrm{OH}-\mathrm{Fe}$ or $\mathrm{Al}-\mathrm{OH}-\mathrm{Al}$; furthermore, there were two peaks at $778 \mathrm{~cm}^{-1}$ and $640 \mathrm{~cm}^{-1}$ for PAC-SCML and two peaks at $770 \mathrm{~cm}^{-1}$ and $578 \mathrm{~cm}^{-1}$ for PAC-IG, which were attributed to bending vibrations of $\mathrm{Fe}-$ $\mathrm{OH}$ and $\mathrm{Al}-\mathrm{OH}$, respectively [24-28].

3.3. Coagulation Characteristics. Coagulation tests were performed by using simulated diatomite water and real oily wastewater samples. The turbidity of the simulated diatomite water samples was $1480 \mathrm{NTU}, 720 \mathrm{NTU}$, and $80 \mathrm{NTU}$. The $\mathrm{COD}_{\mathrm{Cr}}$ of the oily wastewater samples obtained from Liaohe Petroleum Exploration Bureau of China was $534 \mathrm{mg} / \mathrm{L}$ and its turbidity was 124 NTU.

As indicated in the flocculation results in Table 3, the coagulation effect of PAC-IG was much better than that of PAC-SCML for simulated diatomite water with low turbidity. However, the coagulation effect of PAC-SCML had distinguished advantages over that of PAC-IG for simulated diatomite water with high turbidity, which might originate from the formation of PAFC and PSi with strengthening coagulation effect in acid leaching process. Moreover, the small amount of water insoluble $\mathrm{CaF}_{2}$ and $\mathrm{CaSiF}_{6}$ in PACSCML could also benefit the coagulating reaction for high turbidity water.

The $\mathrm{COD}_{\mathrm{Cr}}$ removal of PAC-SCML and PAC-IG both achieved the minimum at $60 \mathrm{mg} / \mathrm{L}$ dosage while PAC-SCML was relatively superior to PAC-IG for oily sewage from Liaohe Oilfield, and the same law was presented for turbidity removal.

The results suggested that despite the small difference in alumina content between PAC-SCML and PAC-IG, PACSCML was superior to PAC-IG in both the comprehensive coagulating character and manufacturing cost due to the certain amount of Fe and Si in PAC-SCML. 
TABLE 3: Coagulation behavior contrast of the produced PAC by SCML versus industrial grade PAC.

\begin{tabular}{|c|c|c|c|c|c|}
\hline \multirow{3}{*}{$\begin{array}{l}\text { Performances } \\
\text { Samples }\end{array}$} & \multirow{2}{*}{\multicolumn{3}{|c|}{$\begin{array}{c}\text { Simulated diatomite water added } 30 \mathrm{mg} / \mathrm{L} \text { flocculant } \\
\text { Residual turbidity (NTU) }\end{array}$}} & \multicolumn{2}{|c|}{ Oily wastewater added $60 \mathrm{mg} / \mathrm{L}$ flocculant } \\
\hline & & & & \multirow{2}{*}{$\begin{array}{l}\text { Residual } \mathrm{COD}_{\mathrm{Cr}} \\
(\mathrm{mg} / \mathrm{L}) \\
534 \text { Initial }\end{array}$} & \multirow{2}{*}{$\begin{array}{l}\text { Residual turbidity } \\
\text { (NTU) } \\
124 \text { Initial }\end{array}$} \\
\hline & 1480 Initial & 720 Initial & 80 Initial & & \\
\hline A & 261 & - & - & 358 & 42 \\
\hline B & 279 & - & - & 355 & 38 \\
\hline $\mathrm{C}$ & 25 & 24 & 15 & 245 & 6 \\
\hline PAC-IG & 34 & 20 & 10 & 330 & 18 \\
\hline
\end{tabular}

\section{Conclusions}

The preparation of PAC coagulant from synthetic cryolite mother liquor from clay-brine process (PAC-SCML) with advanced performances compared with conventional industrial grade PAC (PAC-IG) coagulant was achieved. Reaction conditions including the choice of leaching acid and alkaline polymerization adjusting agent, the $\mathrm{pH}$ value, and the reaction temperature and reaction time were thoroughly studied to optimize the coagulation performances and minimize the insoluble solid in water of the prepared coagulant. The optimized technique to prepare PAC-SCML was that adjusting the concentration of $\mathrm{HCl}$ in synthetic cryolite mother liquor to $18 \%$ with the industrial grade $\mathrm{HCl}$ (the concentration about $32 \%$ to $36 \%$ in general) firstly, and then adding the needed bauxite. Then the acid leaching reaction was kept for $1 \sim 2 \mathrm{~h}$ at $80 \sim 100^{\circ} \mathrm{C}$ and sodium aluminate was consequently added to adjust $\mathrm{pH}$ value to $3.5 \sim 3.8$. The whole technology would be completed after a $24 \mathrm{~h}$ coagulation process. The coagulation performances tested showed that PAC-SCML is better than PAC-IG in turbidity removal at high turbidity simulated diatomite water and in $\mathrm{COD}_{\mathrm{Cr}}$ removal at real oily wastewater. Both XRD and FT-IR results confirmed that there existed certain amount of Fe and Si in PAC-SCML, which could combine $\mathrm{Al}$ to form multiple nuclear inorganic polymer and make the resultant PAC-SCML possess advanced coagulating performances. This technology will become an effective way to treat the large amount of waste acid solution in cryolite fabrication process.

\section{Conflict of Interests}

The authors declare that there is no conflict of interests regarding the publication of this paper.

\section{Acknowledgment}

This research was supported by the National High Technology Research and Development Program (863 Program 2012AA06A109) of China.

\section{References}

[1] H. P. Ding, "Production technology and market situation of cryolite products," Yunnan Metallurgy, vol. 33, no. 3, pp. 64-69, 2004.
[2] Z. Y. Tang, "Producing sand like synthetic cryolite by clay bittern method," Patent CN 1056091 A, 1991.

[3] H. H. Yu, H. Wang, S. Y. Yang et al., "The comprehensive utilization of aluminium fluoride mother liquor," Inorganic Chemicals Industry, vol. 37, no. 4, pp. 34-35, 2005.

[4] T. Dong, J. M. Liu, Z. X. Li et al., "High concentration fluoride wastewater treatment," Tianjin Chemical Industry, vol. 18, no. 5, pp. 58-60, 2004.

[5] M. Zhang, H. N. Yang, X. X. Zhang et al., "Preparation of polyaluminium ferrous chloride by using cryolite mother liquor," Inorganic Chemicals Industry, vol. 42, no. 3, pp. 43-44, 2010.

[6] L. Allouche and F. Taulelle, "Conversion of $\mathrm{Al}_{13}$ Keggin $\varepsilon$ into $\mathrm{Al}_{30}$ : a reaction controlled by aluminum monomers," Inorganic Chemistry Communications, vol. 6, no. 9, pp. 1167-1170, 2003.

[7] W. Seichter, H. J. Mogel, P. Brand, and D. Salah, "Crystal structure and formation of the aluminium hydroxide chloride Al-13(OH)(24)(H2O)(24) Cl-15 center dot 13H(2)O," European Journal of Inorganic Chemistry, no. 6, pp. 795-797, 1998.

[8] W. Z. Wang and P. H. Hsu, "The nature of polynuclear OH-Al complexes in laboratory-hydrolyzed and commercial hydroxyaluminum solutions," Clays \& Clay Minerals, vol. 42, no. 3, pp. 356-368, 1994.

[9] J. E. van Benschoten and J. K. Edzwald, "Chemical aspects of coagulation using aluminum salts-I. Hydrolytic reactions of alum and polyaluminum chloride," Water Research, vol. 24, no. 12, pp. 1519-1526, 1990.

[10] GB15892-2003, "Water treatment chemical-Poly aluminium chlorid. Chinese administration of quality supervision, inspection and quarantine".

[11] R. R. Lu, Y. H. Zhang, F. S. Zhou, X. Wang, Q. An, and Z. Meng, "Novel polyaluminum ferric chloride composite coagulant from Bayer red mud for wastewater treatment," Desalination and Water Treatment, vol. 295, pp. 1-9, 2013.

[12] W. Li, T. Hua, and Q. X. Zhou, "Preparation, morphology and coagulation characteristics of a new polyferric chloride coagulant prepared using pyrite cinders," Environmental Technology, vol. 32, no. 8, pp. 911-920, 2011.

[13] Z. L. Huang, Y. H. Hu, and Z. F. Jiang, "Preparation of polyaluminum chloride from waste chlorhydric acid and poor quality Kaolin," Environmental Protection of Chemical Industry, vol. 22, no. 5, pp. 284-286, 2002.

[14] W. Lan, H. Qiu, J. Zhang et al., "Characteristic of a novel composite inorganic polymer coagulant-PFAC prepared by hydrochloric pickle liquor," Journal of Hazardous Materials, vol. 162, no. 1, pp. 174-179, 2009.

[15] T. Sun, C. Sun, G. Zhu et al., "Preparation and coagulation performance of poly-ferric-aluminum-silicate-sulfate from fly ash," Desalination, vol. 268, no. 1-3, pp. 270-275, 2011. 
[16] G. Zhu, H. Zheng, W. Chen, W. Fan, P. Zhang, and T. Tshukudu, "Preparation of a composite coagulant: polymeric aluminum ferric sulfate (PAFS) for wastewater treatment," Desalination, vol. 285, no. 31, pp. 315-323, 2012.

[17] B. Y. Gao, Z. S. Wang, and H. X. Tang, "Study on the hydrolysis-polymerization process of aluminum and the interaction between hydrolyzed aluminum species and polysilicic acid in flocculant polyaluminum silicate chloride (PASC)," ACTA Scientiae Circumstantiae, vol. 20, no. 2, pp. 151-153, 2000.

[18] F. S. Zhou, L. Ma, J. G. Wu et al., "Complexing agent, preparing method and use thereof," CN1552629, 2004.

[19] F. S. Zhou, L. Ma, J. G. Wu et al., "Complexometric synergist, preparing method and use thereof," CN1552636, 2004.

[20] F. S. Zhou, L. Ma, J. G. Wu et al., Flocculent, preparing method and use thereof. CN1552637, 2004.

[21] D. S. Wang and H. X. Tang, "Poly ferric silicon type compound inorganic high molecular flocculant and its preparing method," CN1210818, 1999.

[22] Z. P. Ai, B. Y. Gao, and S. R. Wang, "Electron microscopic observation on sol and gel of polysilicic acid," Environmental Chemistry, vol. 13, no. 2, pp. 119-122, 1994.

[23] Y. M. Fang, X. D. Zhao, and X. L. Zhang, "Study on the image, structure and coagulation behavior of polysilicate-aluminum ferric," Industrial Safety and Environmental Protection, vol. 33, no. 10, pp. 22-24, 2007.

[24] F. Zhou, S. Wang, J. Su et al., "Structural characteristics of infrared spectra for polyaluminum chloride in enhanced reactions of modification," Spectroscopy and Spectral Analysis, vol. 24, no. 5, pp. 532-535, 2004.

[25] H. Yu, B. Y. Gao, Q. Y. Yue et al., "Study on the structural characteristics of polyaluminum silicata chloride by infraed spectrum method," Journal of Shandong University (Natural Science Edition), vol. 34, no. 2, pp. 198-201, 1999.

[26] W. N. Chen, H. P. Zhong, J. Yang et al., "Analysis of IR spectrum and crystal morphology of polyalumina-silica chlorid (PASC) prepared by various method," Chemical Research and Application, vol. 14, no. 1, pp. 73-75, 2002.

[27] F. S. Zhou, S. H. Wang, J. Z. Su et al., "Infrared spectra and characteristics of PMC-a multicore inorganic polymer flocculant," Fine Chemicals, vol. 20, no. 10, pp. 615-618, 2003.

[28] X. Zhang, L. Zhou, and M. Tang, "Study of infrared spectra of polyaluminum ferric chloride," Spectroscopy and Spectral Analysis, vol. 22, no. 1, pp. 39-42, 2002. 

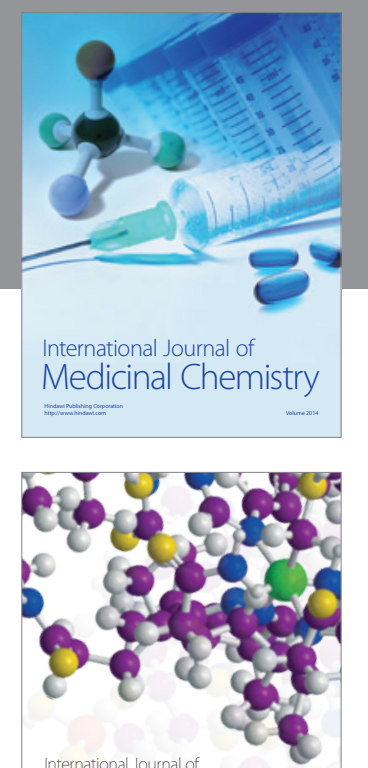

\section{Carbohydrate} Chemistry

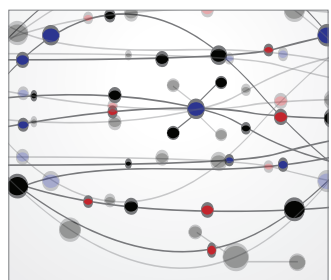

The Scientific World Journal
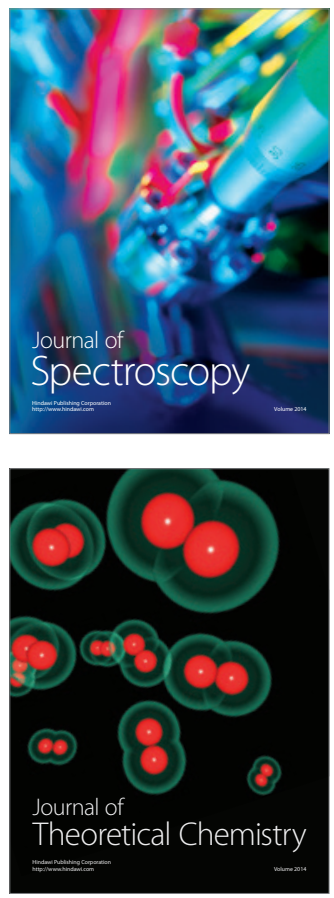
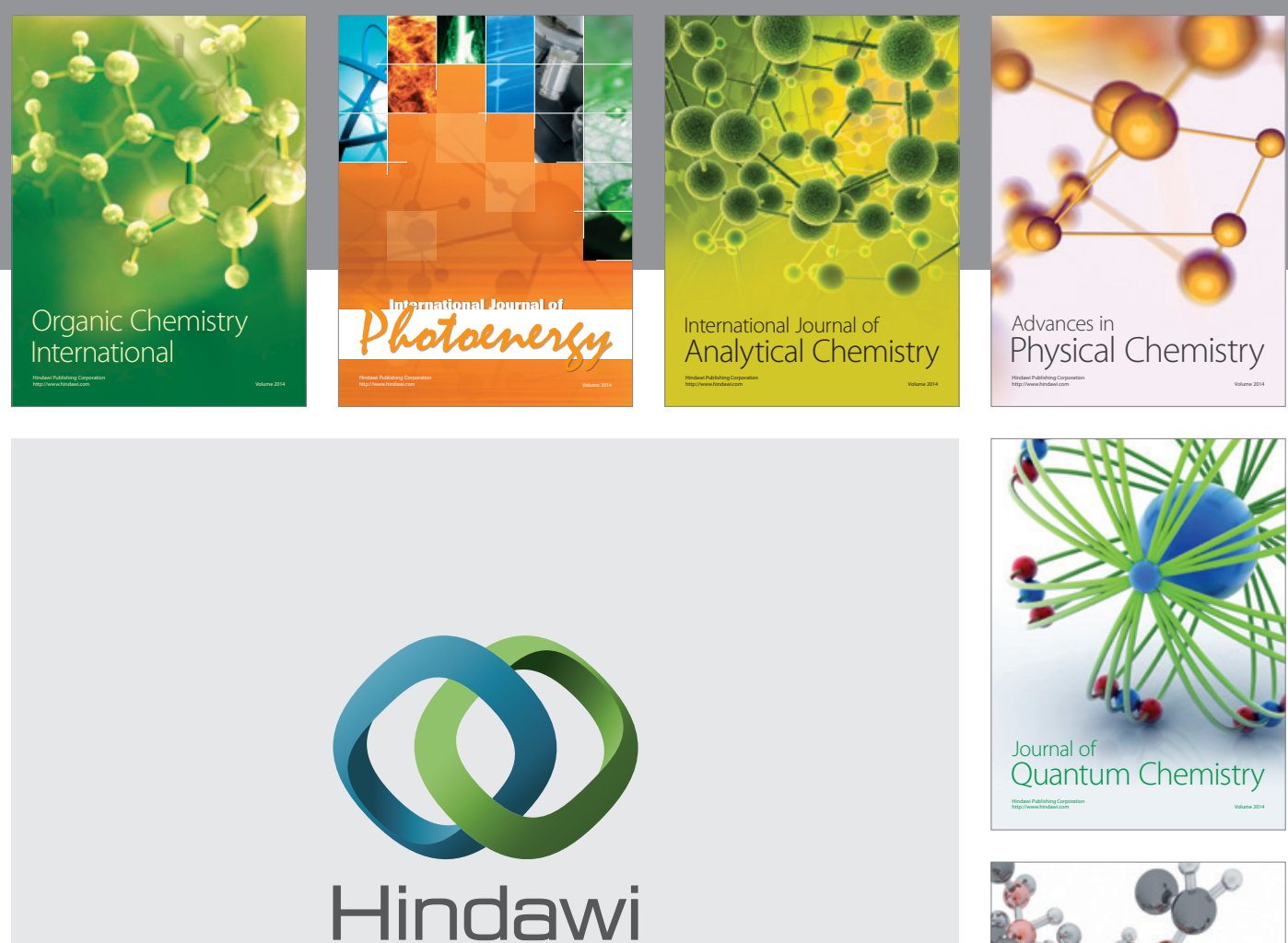

Submit your manuscripts at

http://www.hindawi.com

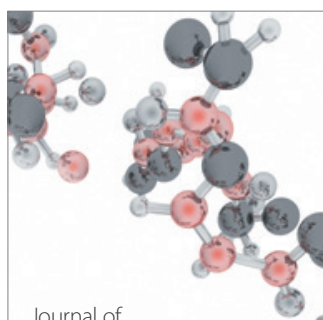

Analytical Methods

in Chemistry

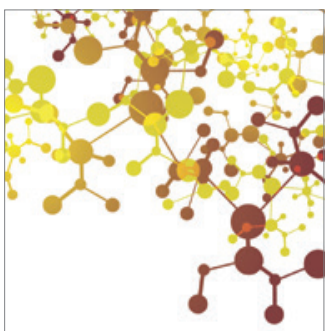

Journal of

Applied Chemistry

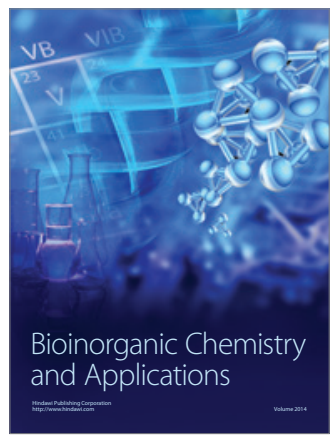

Inorganic Chemistry
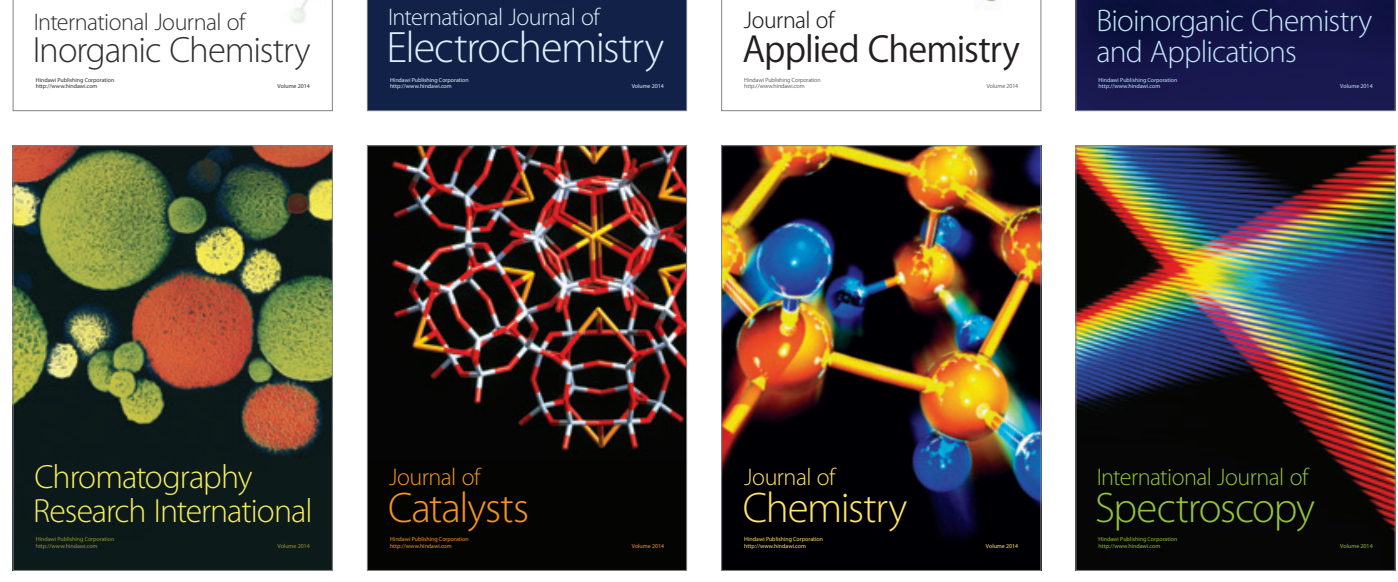